\title{
Unexpected magnetic attraction: Evidence for an organized energy field in the human body
}

\begin{abstract}
Address for correspondence:
James A. Thorp, Department of Obstetrics and Gynecology, Division of Maternal Fetal Medicine, Sisters of St. Mary's Health System, St. Louis, MO

How to cite this article: Thorp JA, Thorp KE, Lile EK, Viglione J. Unexpected magnetic attraction: Evidence for an organized energy field in the human body. G Med Sci. 2021; 2(4): 001-015.

https://www.doi.org/10.46766/thegms.pubheal.21071202
\end{abstract}

Copyright: @ 2021 James A. Thorp, K. E. Thorp, Emily K. Lile, John Viglione. This is an Open Access article distributed under the Creative Commons Attribution License, which permits unrestricted use, distribution, and reproduction in any medium, provided the original work is properly cited.

\section{Abstract}

Introduction \& Background: In recent months unexpected reports have surfaced claiming the presence of magnetic attraction in the shoulder regions of subjects who had recently received the COVID-19 vaccination.

Purpose: To determine if such claims are legitimate or spurious.

Methods: A prospective observational study was performed utilizing standard neodymium magnets and non-magnetized paper clips in a rigorously standardized application protocol. Magnets and paper clips were applied over various regions of both deltoid muscles. The attraction score was calculated by adding one point for each pole of the magnet that attached to each arm over the deltoid muscle for a maximum score of 4 . Likewise, three sizes of paper clips were tested with a maximum score of 6 . The field score was calculated by adding the magnet score to the paper clip score for a maximum score of 10 points.

Results: 256 subjects were enrolled from June 1-July 7, 2021. Of these subjects, 148 (57.8\%) declined the COVID-19 vaccination and 108 (42.2\%) received it. Comparison of the two groups showed no significant differences with the magnet score, the clip score, or the total magnetic score $(P>$ $0.1)$. Multiple regression models used all relevant dependent and independent variables and only autoimmune disease was associated with a reduced field score $(p=0.01)$.

Conclusions: A strong magnetic field is generated in the human body that has no causal relation to previous COVID-19 vaccination.

Keywords: Human magnet attraction, COVID-19 vaccination, human magnetism, human energetic field, human magnetic field, human electromagnetic field.

\section{Introduction}

In the spring of 2021, within months of widescale implementation of vaccination programs for COVID-19, a spate of reports surfaced across communities and in the social media claiming attachment (or attraction) of magnets to vaccinated sites and imputing vaccination as the precipitating cause. While most observers regarded it as a novel curiosity, others speculated that magnetic nanoparticles (or even microchips) had been embedded in vaccines by the manufacturers. Still others dismissed the phenomenon altogether as artifactual and related to friction produced by bodily oils and/or fluids.
Having observed first-hand the phenomenon in vaccinated persons we applied magnets to non-vaccinated individuals and observed the same effect and we thus planned this study to address it more formally. The next question became one of origins: was the external magnet attracted to passive ferrous materials in the deltoid regions or was there an active source of attraction emanating from the muscle, i.e., a magnetic field? To make this discrimination we flipped the disc-shaped magnet onto its opposite side (pole) to observe for non-adherence or repulsion and, secondly, applied passive ferrous materials, i.e., paper clips, to the site of attraction. In both cases attachment (attraction) persisted confirming the presence of an active magnetic field at the site. 
As two of the authors (JT \& KT) had recently published articles, singly and jointly, definitively establishing the presence of an organized energy field in the body, we deduced that the observed magnetic attraction was related not to incidental vaccination but to primary field interactions $[1,2]$. In our review of the scientific medical literature, we were surprised to find a total void of studies addressing this attachment of a magnet to human skin. This is quite bizarre considering that magnets and paperclips have been in existence for centuries. The conclusive demonstration of active magnetic attraction related to an internally generated energy field should thus have far-reaching implications not only in terms of how the human body is conceived but, particularly, on the nature and treatment of disease. This study was designed and executed to substantiate our field hypothesis and to falsify putative links to COVID-19 vaccination.

\section{Materials \& Methods}

Twelve administrators were used for implementation of the study. All followed identical protocols in terms of interviewing and testing of subjects. Participants were recruited by invitation; relevant data was entered into a standardized questionnaire. The intervention subjects exposed their upper arms and shoulders and an alcohol swab was wiped over both shoulder regions to remove oils, reduce moisture, and lessen frictional resistance $[3,4]$. Using the exact same neodymium disc magnets administrators applied them broadly over the surface areas of both deltoid regions to assess for attraction. Attachment was tested using both sides of the magnet. Magnets, manufactured by Mikede, were 32 × 32 × 3mm, 100gm neodymium discs and were purchased through Amazon. The same procedure was then performed using three sizes $(28 \mathrm{~mm}, 33 \mathrm{~mm}$, and $50 \mathrm{~mm})$ of nonmagnetized paper clips (Manufactured by Kempshott also purchased through Amazon). Results were entered into standardized data forms.

The magnet score was calculated as a maximum score of 4 points indicating that both poles of the magnet attached to both deltoids; a score of 1 point if only one pole of the magnet attached to a single deltoid. Likewise, paper clip score was calculated as a maximum score of 6 points if all three paper clip sizes attached to both arms (and 1 point if only one of the paper clip sizes attached to one side only). The field score was calculated by adding the magnet and paper clip scores for a maximum of 10 points.

To address the potential bias of frictional inertia resisting gravitational influences, we employed a model that took into consideration the size, shape, and weight of the magnets. Using standard calculations and published friction coefficients between non-porous metal and skin, the frictional force was determined [3, 4]. Wiping and preparing the skin of study subjects with alcohol reduces the coefficient of friction of the skin $\left(\mu_{\text {skin }}\right)[3,4]$.

Standard statistical methods were used MedCalc ${ }^{\circledR}$ Statistical Software version 20.008 (MedCalc Software Ltd, Ostend, Belgium; https://www.medcalc.org; 2021). Multiple regression analytic models used the magnet score, the paper clip score, and the field score as the dependent variables. The data was interrogated by multiple regression models using forward, backward, stepwise and forced entry of all the relevant dependent and independent variables. To our knowledge there are no previously published studies estimating the event rates and thus, were unable to perform a sample size and power analysis prior to the study. We planned to prospectively collect data on 200 or more subjects and perform a post-hoc power and sample size analysis and to provide adequate statistical power and to interrogate the large number of independent variables with multiple regression analytic models.

\section{Results}

Between June 1 to July 7, 2021, 256 subjects were enrolled in the study. In our population, 148 (57.8\%) declined the COVID-19 vaccination and $108(42.2 \%)$ received it. As expected, the age of the of the 108 vaccinated subjects was significantly greater than the non-vaccinated patients for obvious reasons $(44.2 \pm 17.1$ vs $34.2 \pm 19.3$; $p<0.0001)$. Of the vaccinated patients, $68.5 \%$ received the Pfizer vaccine, $24.1 \%$ Moderna, and $7.4 \%$ Johnson \& Johnson. Demographics of the study population are noted in Table 1 . Table 2 reviews the results of the non-COVID-19 vaccinated group (148) versus the COVID-19 vaccinated group (148 vs 108). Magnet and paper clip attachment to the deltoid muscles occurred in most subjects regardless of vaccination status. No statistical differences between the COVID-19 non-vaccinated and vaccinated groups were observed. Comparison of unvaccinated versus vaccinated groups yielded no significant differences $(\mathrm{p}>0.1)$ in the magnet score of $4 / 4(62.8 \%$ vs $53.7 \%)$; the clip score of $6 / 6(54.1 \%$ vs $46.5 \%)$ and; the field scores of $10 / 10(50.0 \%$ versus $41.7 \%$ ).

Table 2 reviews the various outcomes in non-vaccinated and vaccinated groups. Regardless of how the variables were examined no differences emerged between the non-vaccinated and vaccinated groups. There were nonsignificant trends of higher magnet and field scores in the non-vaccinated group compared to the vaccinated groups ( $p>0.1$ ). We compared laterality of the magnet and paper clip scores in search of an anatomical bias or correlation to the vaccination site but no such relationship existed. Although the study was not designed to evaluate the temporal dynamics of the magnetic fields, we observed that several subjects had significantly different 
magnet scores, clip scores and field scores when tested on subsequent occasions. Extensive interrogation of the data by multiple regression models assessed all the various magnet, clip, and field scores as the dependent variables and all relevant independent variables listed in Tables 1 and 2. Forward, backward, stepwise and forced entry techniques for entry of independent variables were analyzed. Of all the relevant independent variables, only the presence of autoimmune disease was associated with a reduction in field score $(\mathrm{p}=0.01)$.

The force of gravity $\left(\mathrm{F}_{\mathrm{G}}\right)$ was calculated using mass $\mathrm{x}$ acceleration (See Figures 1 and 2). $\mathrm{F}_{\mathrm{G}}=100$ grams (magnet mass) $\times 9.81 \mathrm{~m} / \mathrm{sec}^{2}$ (acceleration of gravity); $\mathrm{F}_{\mathrm{G}}=981$ gram $x \mathrm{~m} / \mathrm{sec}^{2}=0.981 \mathrm{~kg} / \mathrm{sec}^{2}=0.981$ Newton. The skin coefficient of friction $=\mu$ skin $=0.7$; The static force of friction $\left(F_{F}\right)=\mu_{\text {skin }} \times$ magnet weight force $(F M)$; then $F_{G}=F_{F}$ $\mathrm{x} \mu_{\text {Skin }} \mathrm{x}$ FM; given that the magnet weight force downward $\left(\mathrm{F}_{\mathrm{G}}\right)=0.981$ Newtons and $\mu_{\text {skin }}=0.7$, then $\mathrm{F}_{\mathrm{G}}=\mu$ skin $\mathrm{x} F M$ and; $F_{M}=F_{G} / \mu_{\text {skin }}$. Thus, $F_{M} \geq 0.981 / 0.70 \geq 1.4$ Newtons. $F_{F}$ $=0.7 \times 1.4=1.0$ Newtons.

The post-hoc power and sample size analysis using the enrollment of 256 subjects provided us with significant power and robust analytics for data analysis including multiple regression. It would allow us to detect a $15 \%$ reduction in the magnet score, clip score, or field score from about $60 \%$ to $51 \%$ (alpha $<0.05$, beta $>0.2$, and power greater than $80 \%$ ).

Figures 3 and 4 reviews 8 pictures of actual study subjects with the neodymium magnets and paperclips attached. Figure 5 is a video of several subjects with the magnets and paper clips attaching at various sites.

\section{Discussion}

To our knowledge this is the first study describing magnet attachment to the skin in a large prospective observational study. We think that this finding documents the presence of a magnetic field which, by all indications, takes origin in living bodies. An important secondary conclusion from this study is the absence of relationship between the observed attraction response and previous COVID-19 vaccination. Statistical analysis reveals no associations between magnet, clip or field scores and any of the independent variables listed in Tables 1 and 2 with only one exception; there persisted a significant association with the presence of an autoimmune disease and reduced field score on multiple regression $(p=0.01)$.

When we initially described the effect and showed photographs to others the most frequent rebuttals came from dyed-in-the-wool science-based skeptics who casually ascribed it to frictional inertia, even as they observed firsthand the steep pitch of the magnet or paper clip over the deltoid (See photographs). We thus attempted to the extent possible to exclude frictional resistance as a

\section{confounding factor.}

The quantitative models we used to explain vectoral force distribution for magnet adherence to the skin are simplistic and ignore variables such as magnet surface area, frictional properties of the neodymium, pitch of the attachment site and yet show that at any given point of attachment the net magnetic force is always well more than any theoretical frictional component (See Figures 1-4). More pertinent are observations made by nearly all administrators: the magnets and paper clips did not attach to most of the surface area over the deltoids and attraction occured only at certain points. And once a magnet or paper clip attached, if it was moved even $2-4$ centimetres in any direction, it immediately dropped to the floor regardless of pitch. Secondly, peculiar patterns of attraction defied frictional forces as a rational explanation, for example, in many cases the small paper clips would not attach, but the larger ones would attach. Such results exclude any significant contribution related to frictional inertia. The wiping down with alcohol reduced any wetness or oils that might increase the frictional inertia [3, 4]. Figures 3 and 4 reviews 8 pictures of actual study subjects with the neodymium magnets and paperclips attached. Figure 5 is a video of several subjects with the magnets and paper clips attaching at steep angles that favor gravitational forces rather than static frictional forces.

Multiple studies since 2007 describe research with highly magnetic nanoparticles thus fueling allegations that the COVID-19 vaccine was imbedded with these substances [5-17]. Theories ascribing magnet attachment to highly magneticnanoparticles embedded in theCOVID-19vaccine are clearly refuted by this study and could not be rationally challenged. If such materials were at play, attraction would be expected to occur only at vaccination sites and nowhere else. There are numerous reports documenting research using highly magnetic nanoparticles, ferromaterials, and graphenes in medical research and in our environment [5-16]. It is also impossible to determine if highly magnetic nanoparticles in the environment may have contributed to the magnetic effect observed; there are no historical references to document human magnetism before highly magnetic nanoparticles were described. Likewise, it is impossible for this study to address the potential of other environmental factors involving newly developed technologies over the past several decades that may have potentially influenced this human field effect.

Having recognized and confirmed the ubiquity of this magnet attachment phenomenon (it was present in most subjects regardless of vaccine status), it is necessary to move beyond description and attempt to explain its physiologic basis. What specific processes within the body are responsible for generation of the magnetic force responsible for attraction of the neodymium magnets and non-magnetized paper clips? Here developments in cardiology come into play. 
For much of the $20^{\text {th }}$ century the heart was conceived as a mechanical pump that projected blood forward through the arteries during systole by ventricular contraction. Diastole, in turn, was regarded as a period of passive relaxation. In the 1980 s reports surfaced describing negative intraventricular pressures in the early diastolic phase of the heart cycle which researchers soon concluded must account for diastolic filling and the forward movement of blood [17-19]. A 1986 article in Scientific American entitled The Heart as a Suction Pump advanced a new model of cardiac function [20]. Numerous articles followed in support of active dilation and by the late $1980 \mathrm{~s}$ researchers had coined the term 'diastolic dysfunction' to designate a growing number of pathologic states associated with impaired outward movement of the ventricle [21-23]. A mid-1990s paper refuted the systolic propulsion theory of heart function [24]. After the 1990s imaging studies described spiral arterial flow currents which can only be explained on the basis of a suction force [25-29]. The fetal circulation within the human uterus provides even more compelling evidence for active diastolic function in the human fetus. From a mechanical engineering perspective, the propulsive forces of the fetal heart are vastly insufficient to propel blood not only through the entire fetal body circulation, but also through the extra-corporeal placental circulation, back and forth through a $30 \mathrm{~cm}$ umbilical cord. It is a self-evident fact that the feto-placental circulation is an impossible model if explained only on the basis of propulsive cardiac forces; other forces must be involved [30, 31].

Since the introduction of the electrocardiogram in the early $20^{\text {th }}$ century scientists assumed that electrical currents flowing through the nerves along the outer surface of the heart caused the ventricles to contract even though the heart possesses intrinsic rhythmicity and continues to function in the absence of nerves. Nor have scientists considered what happens to the electrical currents seen on ECG after they ostensibly induce ventricular contraction. Surely, they cannot simply disappear but instead, contribute to the body's energy fields.

Evidence suggests that electron currents are drawn through the nerves by the contraction of the heart and infused directly into the blood. The excess of negative charge induces conformational change and repulsion in proteins which initiates active dilation and diastole. Moreover, Faraday's Law indicates that rotary movement of electric currents generates an electromagnetic field. (One could equally say that the magnetic field induces the rotary movement of electricity). The cardiovascular system and blood thus form a primal energy generating system laden with forces that mediate functions throughout the body.

We use the term 'field' to denote a nexus of shared functions. The energy field comprises a group of organs and tissues involved in the generation and flow of non- chemical energetic substance, i.e., electromagnetism, throughout the body. Blood and heart cells are rich in iron and the iron-containing proteins hemoglobin and myoglobin, which are prone to follow magnetic lines of force. Elements in the blood and heart wall act in unison to generate, reinforce and stabilize this commonly shared field. When the heart wall contracts, electrical currents streaming through its muscle fibers spin radially generating an oscillating field that attaches to, and flows through, iron-rich tissues such as blood, heart, liver, and skeletal muscle, all of which share common embryologic origins in the mesoderm $[33,34]$. This primary nexus of relations represents the basis for the organized energy field, the source for all bodily functions and, equally, accounts for the attraction of the neodymium magnets to the deltoid regions. Interestingly several subjects observed magnet attachment at other bodily sites such as the precordium, abdominal wall, and thigh region. Moreover, several individuals observed that their own field scores were dynamic and changed from zero to ten over time.

It has become increasingly clear that not only does this energy field mediate normal physiologic organ functions but, in its deterioration, forms the basis of a host of chronic diseases, especially organ failure syndromes like chronic heart failure, chronic kidney disease, non-alcoholic fatty liver and more. Reports link diastolic dysfunction to the now-ubiquitous metabolic syndrome, first described in the 1980s, and its cluster of associated disturbances including hypertension, insulin resistance, diabetes, \& obesity [35, 36]. Given that the diastolic phase of the cardiac cycle represents a period of active energy infusion into the blood, such chronic syndromes must be regarded as primary energy deficiency states. Medical science still has no effective treatments for these conditions.

Perhaps the most curious result of our study came with the recognition that in a significant percentage of subjects, the magnets attached to the skin on both sides (north and south poles), which seemingly violates known laws of magnetic attraction and repulsion. We have no satisfying explanation for this phenomenon. It should be noted however that virtually all knowledge of magnetism has been derived from observations of interactions between external magnets and such inferences may not be directly applicable to living bodies.

While ferrous elements of the body are undoubtedly involved in field dynamics it cannot be ignored that the actual forces are mediated and expressed by the flow of fluids and water. A more suitable conceptual model might be, for example, the interaction between lunar orbitals and the tides within the earth's magnetic field. Moreover, if the body's energy field possesses an organized resonance structure it is conceivable that the field spontaneously reorients itself as the magnet is flipped. This could potentially explain how the mirror-image congenital 
anomalies occur during embryogenesis, i.e., syndromes involving heterotaxia, dextrocardia and situs inversus, can be conceived as the result of spontaneous 'field flips'. Recent evidence suggests that the earths geomagnetic field is associated with morphogenesis and also that electromagnetic field exposures may have adverse effects on human development $[28,37]$.

It is relevant to inquire as to why the attraction phenomenon, present in most of our subjects, has not been previously described in the scientific literature. For the past 200 years medical science has been dominated by molecular and cellular ideas and it is tempting to speculate that the notion was simply never entertained. But one would also think that before focusing exclusively on molecular and cellular processes scientists would have sought to exclude other relevant causal possibilities, especially given that Roman physician Galen had described the existence of an organized energy field in the body as early as the $2^{\text {nd }}$ century AD.

Galen's system of humoral medicine, which explained all bodily phenomena (including disease) in terms of energy flow, was taken as an article of faith among physicians for over 1500 years until it was arbitrarily rejected by chemists. The rediscovery of this field would seem to corroborate Galen's claims and call into question the primacy of events at the molecular and cellular levels. This becomes more compelling since some experts argue that since the beginning of the modern therapeutic era in the early $20^{\text {th }}$ century that medical scientists have cured very few if any classes of disease. The unexpected phenomenon of magnetic attachment to the human body is difficult (if not impossible) to explain based on molecular and cellular biology.

The major limitation of this study is that it did not address why certain individuals demonstrate magnetic attachment and others do not. Nor did it address variations in relative strength of the fields between individuals or temporal variations in attraction and field strength in single individuals. The study was not designed to determine the causes of natural variation of pathologic causes in human energy fields and for these reasons the finding of autoimmune diseases associated with low field scores cannot be confidently concluded but should be studied in future investigations. The study is also limited in that it cannot determine if other environmental exposures have affected the human energetics fields over the past several decades [38-41].

The strengths of the study include the obvious fact that it is the FIRST and only study of its kind. Secondly, there was recruitment from diverse geographic locations including, Fort Worth TX, Lansing MI, Grand Rapids MI, Williamston MI, Boise ID, Pensacola FL, Gulf Breeze FL, and Gainesville FL. Thirdly, 12 different study administrators mostly began with absolute cynicism and/or a healthy degree of skepticism and they became convinced of the veracity of these findings by their own observations on testing their own subjects. Finally, the sample size provided ample power and robust analytics to make our confident conclusions. 
Table 1. Demographics of study population by COVID-19 vaccination status

\begin{tabular}{|c|c|c|c|}
\hline & $\begin{array}{l}\text { Not Covid Vaccinated } \\
(\mathrm{n}=1 \mathbf{4} 8)\end{array}$ & $\begin{array}{l}\text { Covid Vaccinated } \\
(\mathrm{n}=108)\end{array}$ & $P$ value \\
\hline Age & $34.2 \pm 19.3$ & $44.2 \pm 17.1$ & $<0.0001$ \\
\hline BMI & $26.3 \pm 6.8(122)$ & $27.2 \pm 6.6(88)$ & NS \\
\hline \multicolumn{4}{|l|}{ Gender } \\
\hline Female & $56.1 \%$ & $52.8 \%$ & NS \\
\hline Male & $43.9 \%$ & 47.2 & NS \\
\hline \multicolumn{4}{|l|}{ Race } \\
\hline Caucasian & 136 & 100 & NS \\
\hline African American & 8 & 1 & NS \\
\hline Hispanic & 2 & 3 & NS \\
\hline Asian & 0 & 3 & NS \\
\hline Other & 2 & 1 & NS \\
\hline \multicolumn{4}{|l|}{ Medical Complications } \\
\hline Hypertension & 13 & 9 & NS \\
\hline Diabetes & 4 & 6 & NS \\
\hline Autoimmune disease & 4 & 8 & NS \\
\hline Rheumatoid arthritis & 1 & 2 & NS \\
\hline Thyroid disease & 3 & 2 & NS \\
\hline Fibromyalgia & 0 & 3 & NS \\
\hline Heart disease & 3 & 2 & NS \\
\hline \multicolumn{4}{|l|}{ Tattoos } \\
\hline Left arm & 18 & 11 & NS \\
\hline Right arm & 18 & 11 & NS \\
\hline Metallic implants & 8 & 13 & NS \\
\hline \multicolumn{4}{|l|}{ Vaccine Type } \\
\hline Pfizer & & $74(68.5 \%)$ & \\
\hline Moderna & & $26(24.1 \%)$ & \\
\hline Johnson \& Johnson & & $8(7.4 \%)$ & \\
\hline Days from $1^{\text {st }}$ Vax to test (days) & & $97.0 \pm 43.3$ & \\
\hline Days from $2^{\text {nd }}$ Vax to test (days) & & $75.7 \pm 42.8$ & \\
\hline Vaccination complications & & $23(21.3 \%)^{\S}$ & \\
\hline
\end{tabular}

[All data represent mean $\pm 1 \mathrm{SD}$ or $\mathrm{N}(\%)$. NS $=$ non-significant $\mathrm{p}$ value $>0.2$ ] [ ${ }^{8}$ Only minor complications were reported by the subjects] 


\section{Table 2. Results of Study Population by COVID-19 vaccination status}

\begin{tabular}{|c|c|c|c|}
\hline & $\begin{array}{l}\text { Not Covid Vaccinated(n } \\
=148)\end{array}$ & $\begin{array}{l}\text { Covid Vaccinated } \\
(n=108)\end{array}$ & Pvalue \\
\hline Prepared with alcohol wipes & $122(100 \%)$ & $99(100 \%)$ & NS \\
\hline Neodymium magnet repulsion force & 0 & 0 & NS \\
\hline \multicolumn{4}{|l|}{ Neodymium Magnet scores } \\
\hline Magnet test right arm score of $2 / 2$ & $100(67.6 \%)$ & $61(56.5 \%)$ & NS \\
\hline Magnet test to left arm score of $2 / 2$ & $98(66.2 \%)$ & $66(61.1 \%)$ & NS \\
\hline Magnet score of $4 / 4$ & $93(62.8 \%)$ & $58(53.7 \%)$ & NS \\
\hline Magnet score of $0 / 4$ & $32(21.6 \%)$ & $31(28.7 \%)$ & NS \\
\hline \multicolumn{4}{|l|}{ Un-magnetized Paper Clip Scores } \\
\hline Small paper clip attached to right arm & $97(65.5 \%)$ & $68(63.0 \%)$ & NS \\
\hline Small paper clip attached to left arm & $102(68.9 \%)$ & $71(65.7 \%)$ & NS \\
\hline Medium paper clip attached to right arm & $93(62.3 \%)$ & $68(60.6 \%)$ & NS \\
\hline Medium paper clip attached to left arm & $99(66.9 \%)$ & $66(61.1 \%)$ & NS \\
\hline Large paper clip attached to right arm & $90(60.7 \%)$ & $67(59.6 \%)$ & NS \\
\hline Large paper clip attached to left arm & $95(66.4 \%)$ & $62(54.5 \%)$ & NS \\
\hline Paper clip score on right arm $3 / 3$ & $86(57.4 \%)$ & $64(56.6 \%)$ & NS \\
\hline Paper clip score on left arm $3 / 3$ & $89(61.5 \%)$ & $61(53.5 \%)$ & NS \\
\hline Paper clip score of $6 / 6$ & $80(54.1 \%)$ & $54(46.5 \%)$ & NS \\
\hline Paper clip score of $0 / 6$ & $33(21.3 \%)$ & $30(29.3 \%)$ & NS \\
\hline \multicolumn{4}{|l|}{ Field Scores (magnet + clip scores) } \\
\hline Total Field score 10/10 & $74(50.0 \%)$ & $45(41.7 \%)$ & NS \\
\hline Total Field score $0 / 10$ & $22(13.1 \%)$ & $25(23.1 \%)$ & NS \\
\hline Right Field Score 5/5 & $80(52.5 \%)$ & $55(47.5 \%)$ & NS \\
\hline Right Field score $0 / 5$ & $30(20.3 \%)$ & $32(29.6 \%)$ & NS \\
\hline Left Field Score 5/5 & $79(53.4 \%)$ & $55(50.9 \%)$ & NS \\
\hline Left Field Score $0 / 5$ & $29(19.6 \%)$ & $26(24.1 \%)$ & NS \\
\hline
\end{tabular}

[All data represent mean $\pm 1 \mathrm{SD}$ or $\mathrm{N}(\%)$. NS $=$ non-significant $\mathrm{p}$ value $>0.1$ ] 
Table 3. Results of Study Population by COVID-19 vaccination status

\begin{tabular}{|c|c|c|}
\hline & $\begin{array}{l}\text { Not Covid Vaccinated } \\
(\mathrm{n}=148)\end{array}$ & $\begin{array}{l}\text { Covid Vaccinated } \\
(\mathrm{n}=108)\end{array}$ \\
\hline \multicolumn{3}{|l|}{ Administrator* } \\
\hline $\operatorname{JET}(\mathrm{n}=83)$ & 63 & 20 \\
\hline $\mathrm{KT}(\mathrm{n}=57)$ & 26 & 31 \\
\hline $\mathrm{EL}(\mathrm{n}=34)$ & 16 & 18 \\
\hline JAT $(n=19)$ & 14 & 5 \\
\hline $\mathrm{LP}(\mathrm{n}=17)$ & 7 & 10 \\
\hline $\mathrm{AC}(\mathrm{n}=12)$ & 9 & 3 \\
\hline EO $(n=10)$ & 0 & 10 \\
\hline $\mathrm{JK}(\mathrm{n}=8)$ & 1 & 7 \\
\hline $\mathrm{JB}(\mathrm{n}=6)$ & 6 & 0 \\
\hline$J V(n=6)$ & 4 & 2 \\
\hline $\mathrm{DA}(\mathrm{n}=3)$ & 1 & 2 \\
\hline $\mathrm{BD}(\mathrm{n}=1)$ & 1 & 0 \\
\hline \multicolumn{3}{|l|}{ Location of test* } \\
\hline Lansing, MI $(\mathrm{n}=117)$ & 80 & 37 \\
\hline Williamston, MI $(\mathrm{n}=24)$ & 9 & 15 \\
\hline Gulf Breeze, FL $(n=33)$ & 24 & 8 \\
\hline Gainesville, FL ( $\mathrm{n}=34$ ) & 16 & 18 \\
\hline Fort Worth, TX $(n=17)$ & 7 & 10 \\
\hline McDavid, FL $(\mathrm{n}=11)$ & 9 & 2 \\
\hline Grand Rapids, MI $(\mathrm{n}=10)$ & 0 & 10 \\
\hline Boise, ID $(\mathrm{n}=8)$ & 1 & 7 \\
\hline
\end{tabular}

[All data represent sample size (n).] 


\section{Figure 1. Demonstration of the forces involved with the magnet attachment to the skin}

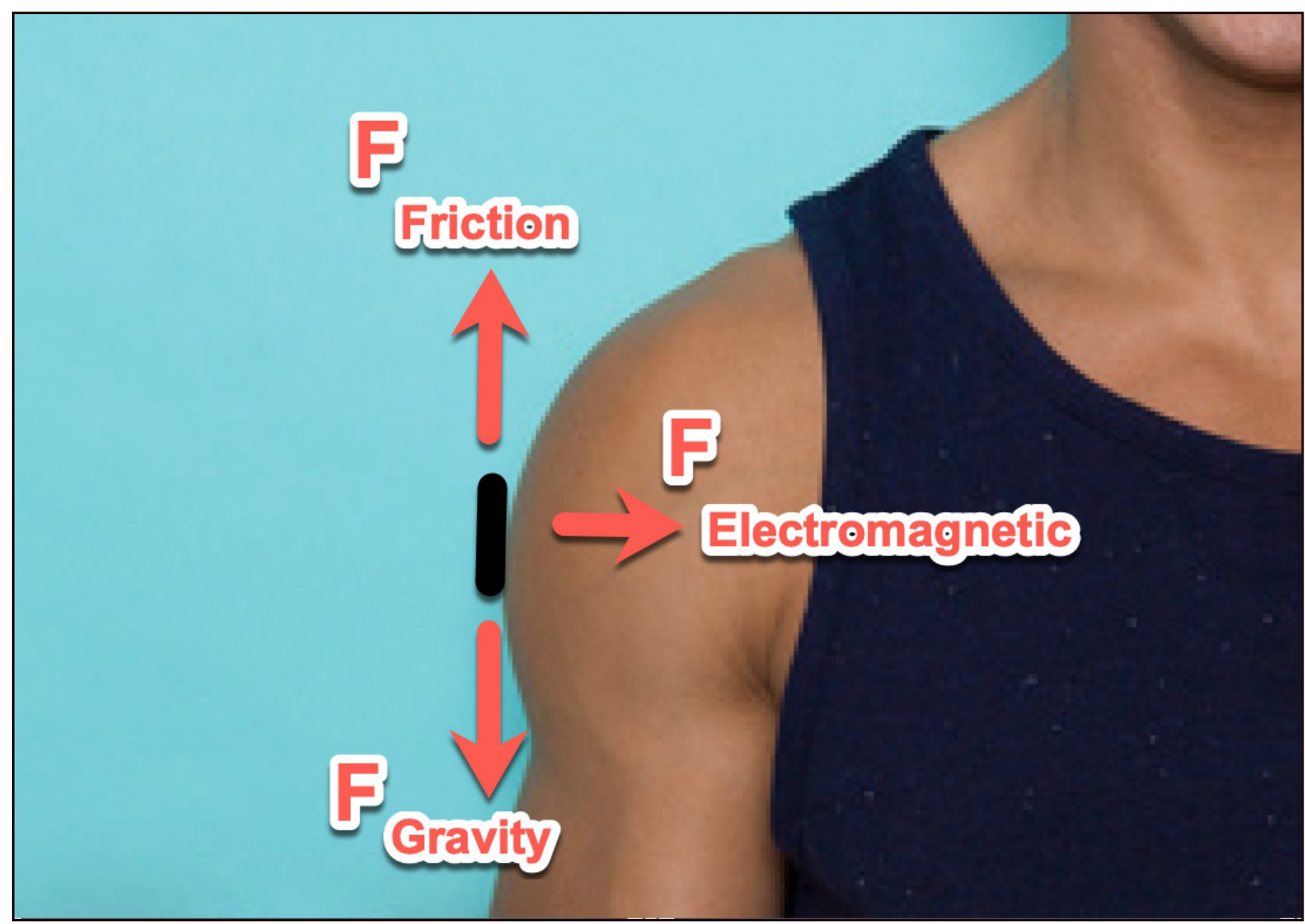

The force of gravity $\left(\mathrm{F}_{\mathrm{G}}\right)=$ mass $\mathrm{x}$ acceleration $\mathrm{F}_{\mathrm{G}}=100$ grams (neodymium magnet) $\times 9.81 \mathrm{~m} / \mathrm{sec}^{2}$

$\mathrm{F}_{\mathrm{G}}=981$ gram $\mathrm{x} \mathrm{m} / \mathrm{sec}^{2}=0.981 \mathrm{~kg} / \mathrm{sec}^{2}=0.981$ Newton

The skin coefficient of friction $=\mu_{\text {skin }}=0.7$

The static force of friction $\left(\mathrm{F}_{\mathrm{F}}\right)=\mu_{\text {skin }} \times$ magnetic force $\left(\mathrm{F}_{\mathrm{M}}\right)$

Then $\mathrm{F}_{\mathrm{G}}=\mathrm{F}_{\mathrm{F}} \times \mu_{\text {skin }} \times \mathrm{F}_{\mathrm{M}}$

Given that the magnet force downward $\left(\mathrm{F}_{\mathrm{G}}\right)=0.981$ Newtons and $\mu_{\text {skin }}=0.7$

Then the $\mathrm{F}_{\mathrm{G}}=\mu_{\text {skin }} \mathrm{xF}_{\mathrm{M}}$ and; $\mathrm{F}_{\mathrm{M}}=\mathrm{F}_{\mathrm{G}} / \mu_{\text {skin }}$

$\mathrm{F}_{\mathrm{M}}=0.981 / 0.70=1.4$ Newtons 
Figure 2. Demonstration of neodymium magnet attachment to the skin

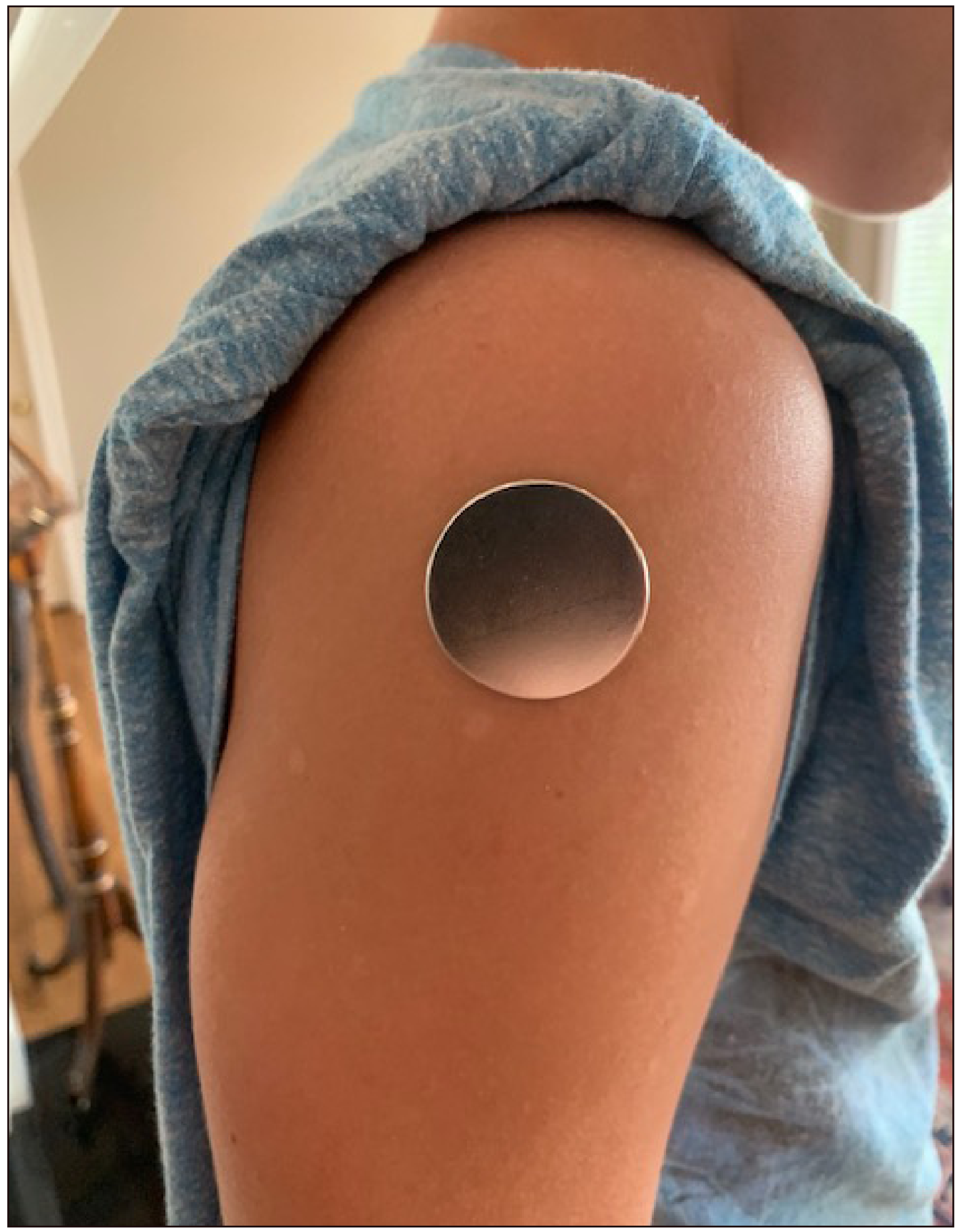


Figure 3. Demonstration of neodymium magnet attachment to the skin on 4 Subjects.

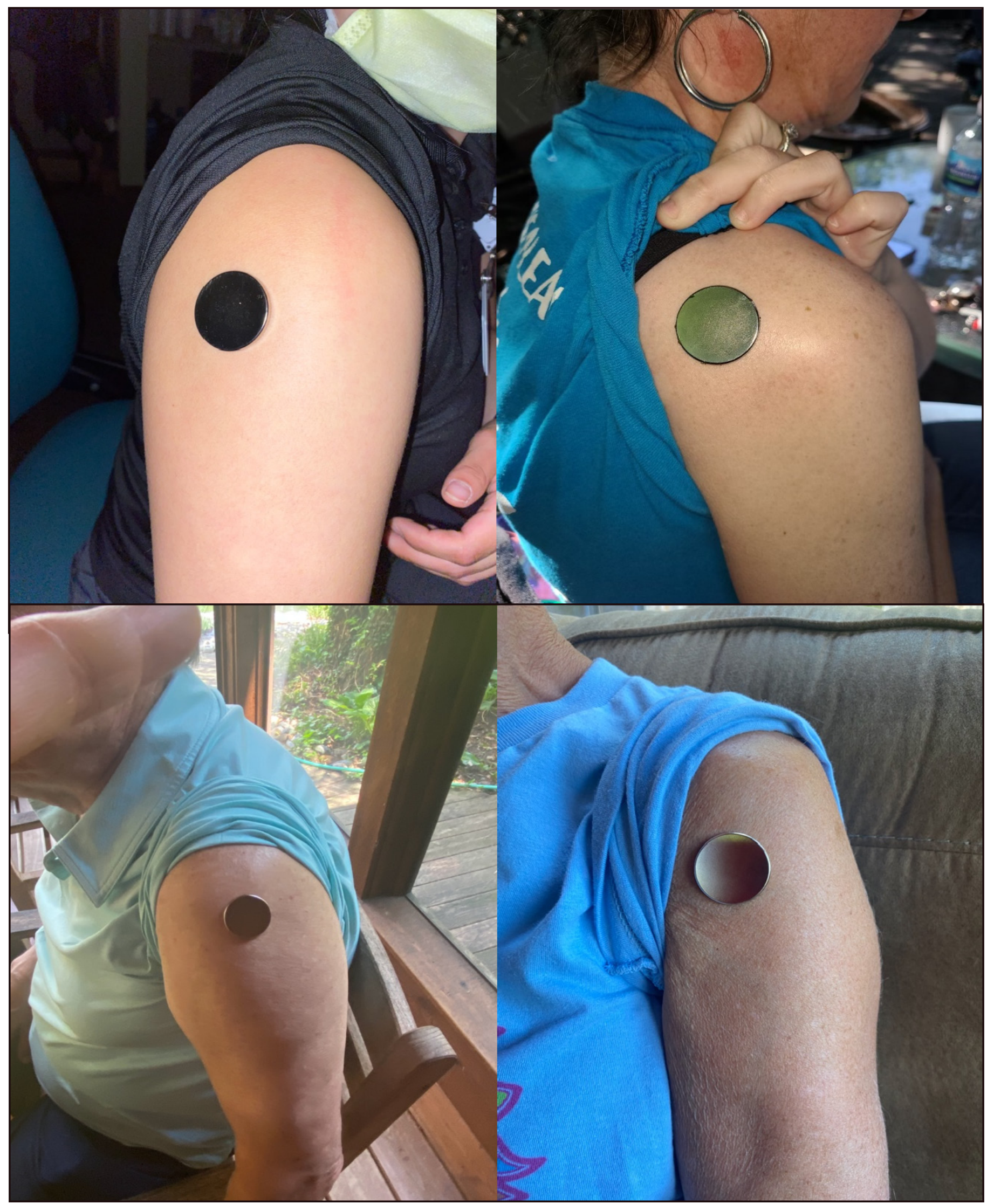


Figure 4. Demonstration of non-magnetized paper clip attachment to the skin on 4 Subjects.

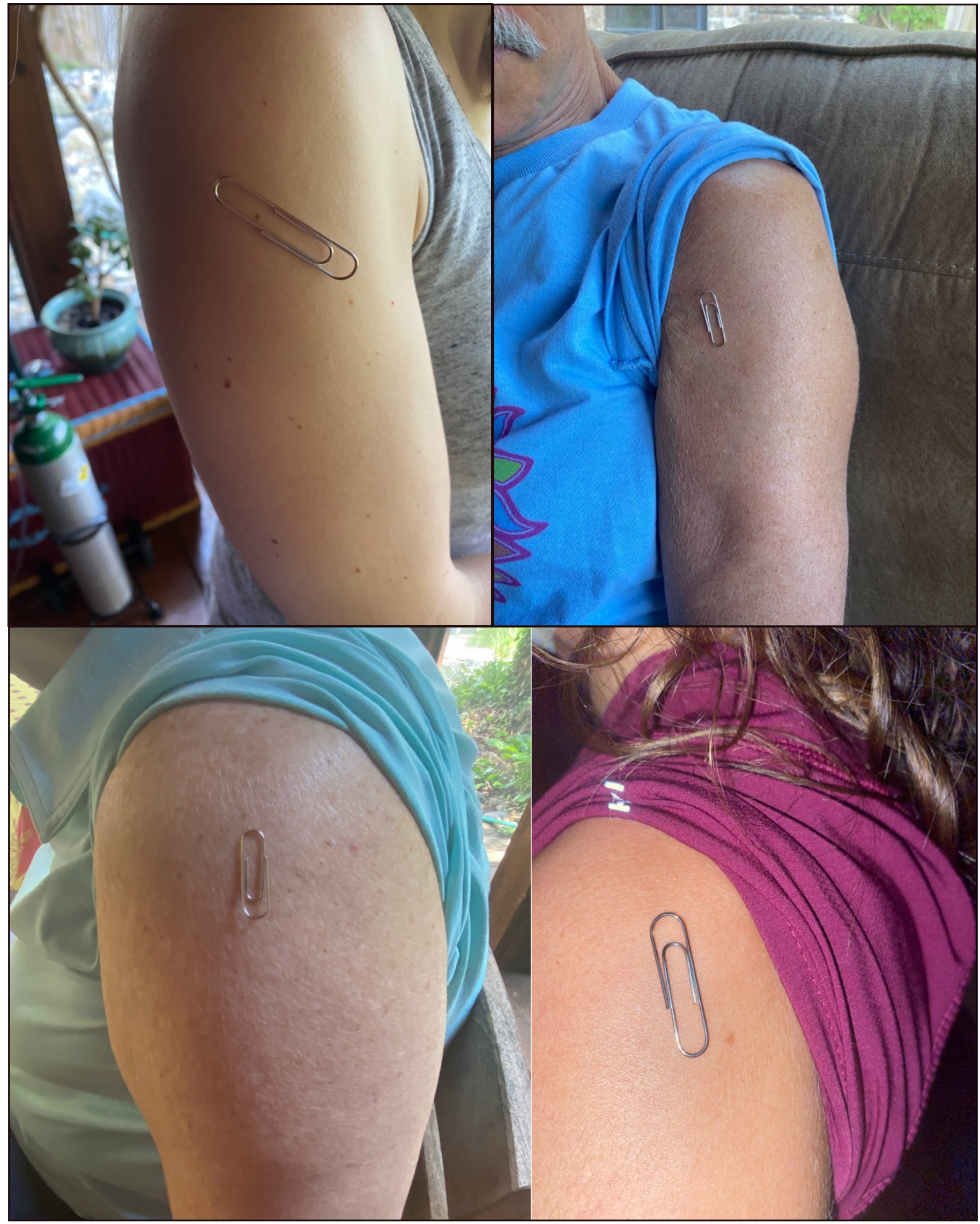


Video 1. Video documenting magnet and paper clip attachment in five of our subjects

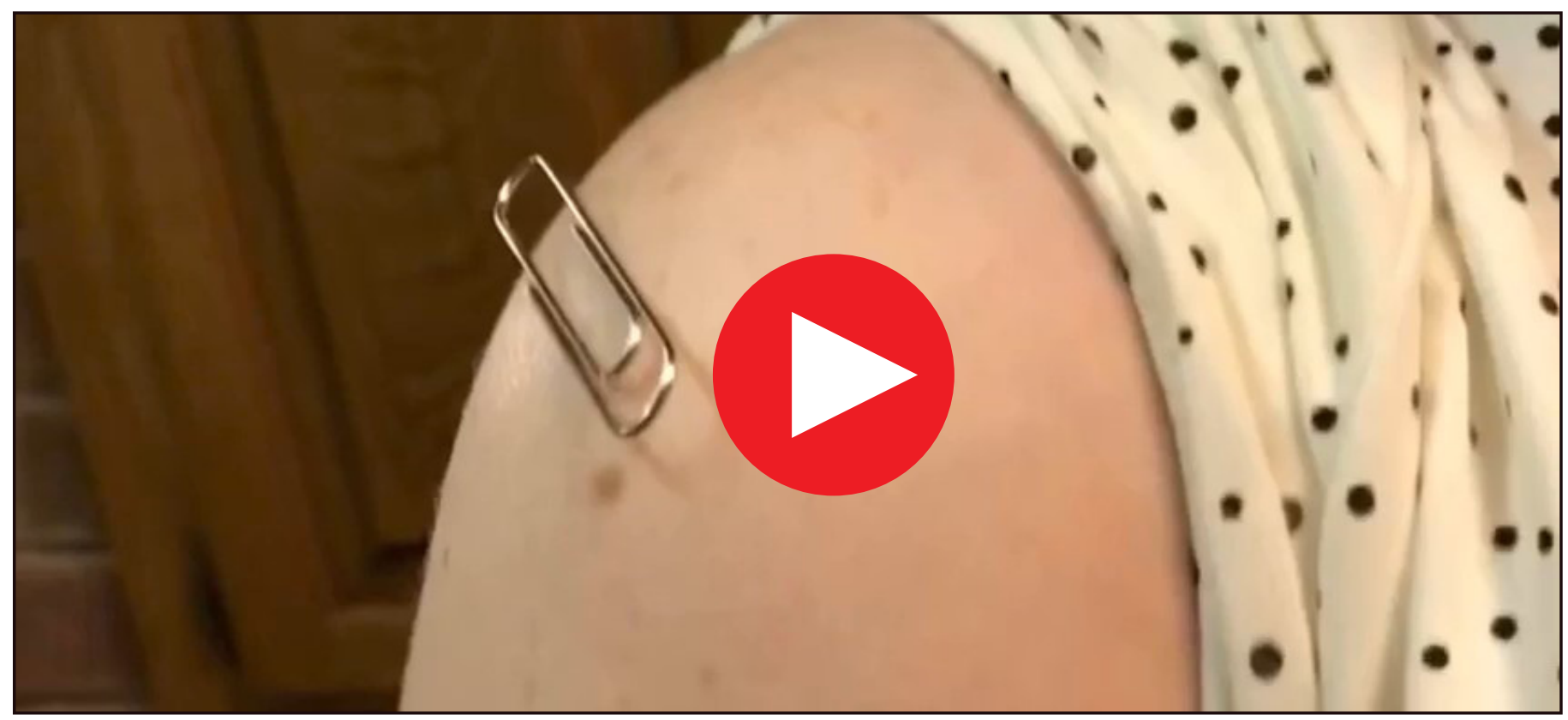

\section{References}

1. Thorp KE. Morphogenic fields: A coming of age. Explore 2021 Apr.7:S1550-8307(21)00078-1.

2. Thorp KE, Thorp JA. Ozone Preconditioning: Waking up the dragon. G Med Sci. 2021; 2(3): 010-039. https://www.doi.org/10.46766/thegms. intmed.21051402

3. Seo NJ, Armstrong TJ, Drinkaus P. A comparison of two methods of measuring static coefficient of friction at low normal forces: a pilot study. Ergonomics. 2009 Jan;52(1):121-35. doi: 10.1080/00140130802238622. PMID: 19308825.

4. Sivamani RK, Goodman J, Gitis NV, Maibach HI. Friction coefficient of skin in real-time. Skin Res Technol.2003 Aug;9(3):235-9. doi: 10.1034/j.1600-0846.2003.20361.x. PMID: 12877684.

5. Manousi N, Rosenberg E, Deliyanni E, Zachariadis GA, Samanidou V. Magnetic Solid-Phase Extraction of Organic Compounds Based on Graphene Oxide Nanocomposites. Molecules. 2020 Mar 4;25(5):1148. doi: 10.3390/molecules25051148. PMID: 32143401; PMCID: PMC7179219.

6. Yin P, Sun N, Deng C, Li Y, Zhang X, Yang P. Facile preparation of magnetic graphene double-sided mesoporous composites for the selective enrichment and analysis of endogenous peptides. Proteomics. 2013 Aug;13(15):2243-50. doi: 10.1002/pmic.201300066. Epub 2013 Jul 1. PMID: 23716354 .

7. Alsharif NA, Merzaban JS, Kosel J. Biofunctionalization of Magnetic Nanomaterials. J Vis Exp. 2020 Jul 16;(161). doi: 10.3791/61360. PMID: 32744515 .

8. Al-Deen FN, Ho J, Selomulya C, Ma C, Coppel R. Superparamagnetic nanoparticles for effective delivery of malaria DNA vaccine. Langmuir. 2011 Apr 5;27(7):3703-12. doi: 10.1021/la104479c. Epub 2011 Mar 1. PMID: 21361304.

9. Al-Deen FN, Selomulya C, Ma C, Coppel RL. Superparamagnetic nanoparticle delivery of DNA vaccine. Methods Mol Biol. 2014;1143:181-94. doi: 10.1007/978-1-4939-0410-5_12. PMID: 24715289 .

10. Lu AH, Salabas EL, Schüth F. Magnetic nanoparticles: synthesis, protection, functionalization, and application. Angew Chem Int Ed Engl. 2007;46(8):1222-44. doi: 10.1002/anie.200602866. PMID: 17278160.

11. Pereira C, Pereira AM, Quaresma P, Tavares PB, Pereira E, Araújo JP, Freire C. Superparamagnetic gamma-Fe2O3@SiO2 nanoparticles: a novel 
support for the immobilization of [ $\mathrm{VO}$ (acac)2]. Dalton Trans. 2010 Mar 21;39(11):2842-54. doi: 10.1039/b920853d. Epub 2010 Feb 5. PMID: 20200711.

12. Christiansen MG, Senko AW, Anikeeva P. Magnetic Strategies for Nervous System Control. Annu Rev Neurosci. 2019 Jul 8;42:271-293. doi: 10.1146/ annurev-neuro-070918-050241. Epub 2019 Apr 2. PMID: 30939100; PMCID: PMC6617523.

13. Marrella A, Iafisco M, Adamiano A, Rossi S, Aiello M, Barandalla-Sobrados M, Carullo P, Miragoli M, Tampieri A, Scaglione S, Catalucci D. A combined low-frequency electromagnetic and fluidic stimulation for a controlled drug release from superparamagnetic calcium phosphate nanoparticles: potential application for cardiovascular diseases. J R Soc Interface. 2018 Jul;15(144):20180236. doi: 10.1098/rsif.2018.0236. PMID: 29997259; PMCID: PMC6073647.

14. Nimpf S, Keays DA. Is magnetogenetics the new optogenetics? EMBO J. 2017 Jun 14;36(12):16431646. doi: 10.15252/embj.201797177. Epub 2017 May 23. PMID: 28536151; PMCID: PMC5470037.

15. Lee J, Lee Y, Youn JK, Na HB, Yu T, Kim H, Lee SM, Koo YM, Kwak JH, Park HG, Chang HN, Hwang M, Park JG, Kim J, Hyeon T. Simple synthesis of functionalized superparamagnetic magnetite/ silica core/shell nanoparticles and their application as magnetically separable high-performance biocatalysts. Small. 2008 Jan;4(1):143-52. doi: 10.1002/smll.200700456. PMID: 18189246.

16. Wang C, Yan J, Cui X, Wang H. Synthesis of raspberry-like monodisperse magnetic hollow hybrid nanospheres by coating polystyrene template with $\mathrm{Fe}(3) \mathrm{O}(4) \mathrm{SiO}(2)$ particles. J Colloid Interface Sci. 2011 Feb 1;354(1):94-9. doi: 10.1016/j. jcis.2010.09.078. Epub 2010 Oct 8. PMID: 21044785.

17. Stein PD, Sabbah HN, Anbe DT. Negative intraventricular diastolic pressure in patients with mitral stenosis: evidence of left ventricular diastolic suction. Am J Cardiol 1980; 45(3):pp 562-66.

18. Sabbah HN, Anbe DT, Stein PD. Negative intraventricular diastolic pressure in patients with mi- tral stenosis: evidence of left ventricular diastolic suction. Am J Cardiol 1980.45(3):562-66.

19. Hori M, Yellin EL, Sonnenblick EH. Left ventricular diastolic suction as a mechanism of ventricular filling. Jpn Circ J 46(1):124-129;1982.

20. Robinson TF, Factor SM, Sonnenblick EH. The heart as a suction pump. Sci Am 1986 Jun;254(6):8491.doi: 10.1038/scientificamerican 0686-84. PMID: 3704622. Spiral flow in laminar arteries?

21. Stonebridge PA, Brophy CM. Spiral laminar flow in arteries? Lancet Nov 1991. 30;338(8779):13601. doi: 10.1016/0140-6736(91)92238-w. PMID: 1682738.

22. Stonebridge PA, Hoskins PR, Allan PL, Belck JF Spiral laminar flow in vivo. Clin Sci (Lond) 1996. 91(1):17-21;1996.

23. Little WC, Cheng CP. Diastolic Dysfunction. Cardiol Rev 1988. 6(4):231-239.

24. Marinelli R, Fürst B, van der Zee H, McGinn H, Marinelli $\mathrm{W}$. The heart is not a pump: a refutation of the pressure propulsion premise of heart function. Frontier Perspectives Fall-Winter 1995. 5(1):15-24.

25. Kilner PJ, Yang GZ, Mohiaddin RH, Firmin DN, Longmore DB. Helical and retrograde secondary flow patterns in the aortic arch studied by three-directional magnetic resonance velocity mapping. Circulation 1993. 88(5):2235-47.

26. Liu X, Sun A, Fan Y, Deng X. Physiological significance of helical flow in the arterial system and its potential clinical applications. Ann Biomed Engineer 2015. 43(1):3-15.

27. Burleson KO, Schwartz GE. Cardiac torsion and electromagnetic fields: the cardiac bioinformation hypothesis. Med Hypotheses. 2005;64(6):110916. doi: 10.1016/j.mehy.2004.12.023. PMID: 15823696 .

28. Hammerschlag R, Levin M, McCraty R, Bat N, Ives JA, Lutgendorf SK, Oschman JL. Biofield Physiology: A Framework for an Emerging Discipline. Glob Adv Health Med. 2015 Nov;4(Suppl):35-41. doi: 10.7453/gahmj.2015.015.suppl. Epub 2015 
Nov 1. PMID: 26665040; PMCID: PMC4654783.

29. Oki T. State of the art: 'diastology' research 1998. J Med Invest 1998.45(1-4):9-25.

30. Dellschaft NS, Hutchinson G, Shah S, Jones NW, Bradley C, Leach L, Platt C, Bowtell R, Gowland PA. The haemodynamics of the human placenta in utero. PLoS Biol. 2020 May 28;18(5):e3000676. doi: 10.1371/journal.pbio.3000676. PMID: 32463837; PMCID: PMC7255609.

31. Li TG, Nie F, Xu XY. Correlation between ductus venosus spectrum and right ventricular diastolic function in isolated single-umbilical-artery foetus and normal foetus in third trimester. World J Clin Cases. 2020 Dec 6;8(23):5866-5875. doi: 10.12998/wjcc.v8.i23.5866. PMID: 33344585; PMCID: PMC7723705.

32. Orlov OI, Gurieva TS, Dadasheva OA, Spassky AV, Ezdakova MV, Litvin ED, Sychev VN. Influence of a 1000 Times Weakened Magnetic Field on Embryogenesis and Ontogenesis of the Japanese Quail in Several Generations. Dokl Biol Sci. 2020 Jan;490(1):19-24. doi: 10.1134/ S0012496620010068. Epub 2020 Apr 27. PMID: 32342321 .

33. Meynard D, Babitt JL, Lin HY. The liver: conductor of systemic iron balance. Blood 2014 Jan 9;123(2):168-76.

34. Papanikolaou G, Pantopoulos K. Systemic iron homeostasis and erythropoiesis. IUBMB Life 2017 Jun;69(6):399-413.

35. Reaven GM. Banting lecture 1988. Role of insulin resistance in human disease. Diabetes. Banting
Lecture 1988: Role of Insulin Resistance in $\mathrm{Hu}$ man Disease.

36. Reaven GM. Role of insulin resistance in human disease (syndrome $\mathrm{X}$ ): an expanded definition. Annu Rev Med. 1993;44:121-31. doi: 10.1146/annurev.me.44.020193.001005. PMID: 8476236.

37. Amshanov VA. [Geomagnetic field variations in the human prenatal period and cancer in adults]. Vopr Onkol. 2007;53(2):181-4. Russian. PMID: 17663172.

38. Wall S, Wang ZM, Kendig T, Dobraca D, Lipsett $M$. Real-world cell phone radiofrequency electromagnetic field exposures. Environ Res. 2019 Apr;171:581-592. doi: 10.1016/j.envres.2018.09.015. Epub 2018 Oct 3. PMID: 30448205.

39. Gulati S, Yadav A, Kumar N, Priya K, Aggarwal NK, Gupta R. Phenotypic and genotypic characterization of antioxidant enzyme system in human population exposed to radiation from mobile towers. Mol Cell Biochem. 2018 Mar;440(1-2):1-9. doi: 10.1007/s11010-017-3150-6. Epub 2017 Aug 17. PMID: 28819931.

40. MoonJH.Health effects of electromagnetic fields on children. Clin Exp Pediatr. 2020 Nov;63(11):422428. doi: 10.3345/cep.2019.01494. Epub 2020 May 26. PMID: 32683815; PMCID: PMC7642138.

41. Deruelle F. The different sources of electromagnetic fields: Dangers are not limited to physical health. Electromagn Biol Med. 2020 Apr 2;39(2):166175. doi: 10.1080/15368378.2020.1737811. Epub 2020 Mar 10. PMID: 32151189. 